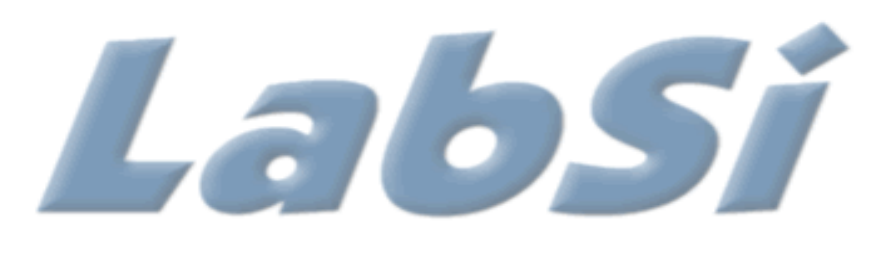

EXPERIMENTAL ECONOMICS LABORATORY.

Francesco Farina

Niall O' Higgins

Patrizia Sbriglia

Eliciting motives for trust and reciprocity

by attitudinal and behavioural measures

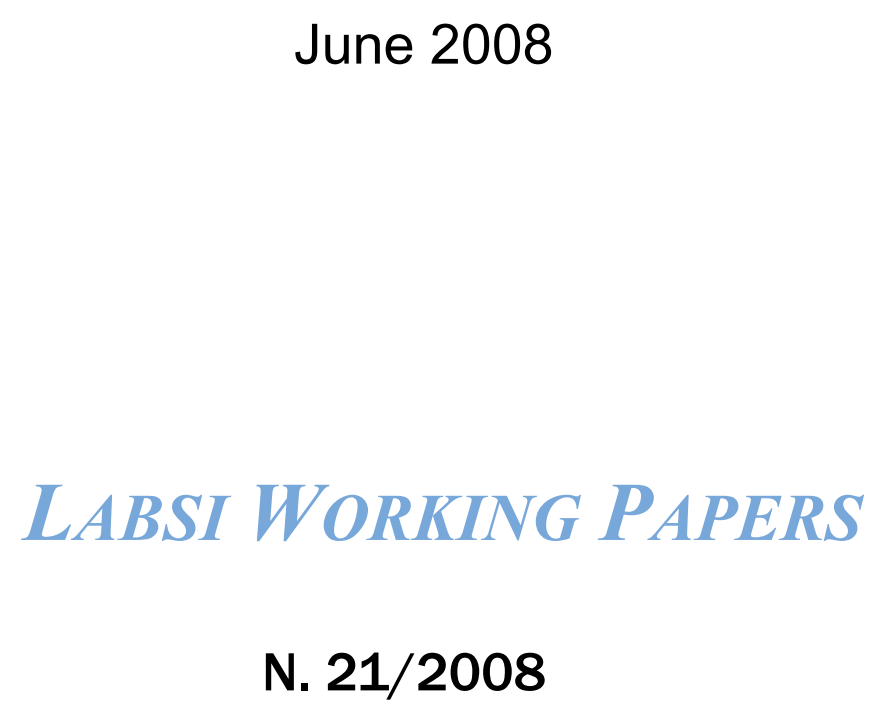


FRANCESCO FARINA

University of Siena
NIALL O'HIGGINS

University of Salerno
PATRIZIA SBRIGLIA

University of Naples II

\section{ELICITING MOTIVES FOR TRUST AND RECIPROCITY BY ATTITUDINAL AND BEHAVIOURAL MEASURES}

"Suit the action to the word, the word to the action,"

(Shakespeare, 1601, Hamlet Act 3, Scene 2).

JEL classification: C42; C72; C91; D63; D64; D83

Keywords : Experimental economics ; Surveys; Trust ; Reciprocity

\section{June 2008}




\section{Introduction}

Value Surveys may reveal well-behaved societies by the statistical treatment of the agents' declarations of compliance with civic habits and social norms. Similarly, the results of experiments conducted on games with conflict of interest trace back to two important primitives of social capital - trust and reciprocity - which can be used to explain deviations from the Nash equilibrium and which lead to the cooperative optimal outcome. The main difference between the experiments performed in Behavioural Economics vis-à-vis the Questionnaires lays in the fact that the latter consist of the each agent's self-evaluation of his trusting attitude as a person and of being trustworthy as a participant in his social environment, while the former directly register the two (or more) players' behaviour in a social interaction. When comparing results stemming from these two empirical research methods, this asymmetry, arising from the lack of a strategic setting in the former and its presence in the latter, has to be carefully tackled. Indeed, "social capital (...) is embodied in the relations among persons" (Coleman, 1990, p.304; italics in the text).

When strategic settings are at stake, relevant questions await an answer. To what extent does individual behaviour, shaped by trust and reciprocity, depart from strict self-interest? Do trust and reciprocity orient the relations among persons towards the strategic reasoning which is needed to mutually improve on the respective pay-offs, or do they trump any strategic reasoning and draw out from the individual his other-regarding (social) preferences? (Farina and Sbriglia, 2008).

In experiments conducted on the Trust Game the behaviour of players often deviates from the Nash solution of the first mover sending nothing. The sender neglects the sub-game perfect strategy profile and sends a positive amount, and the responder renounces his dominant strategy and sends back a positive amount. In the literature this violation of orthodox rational choice is mostly been explained by evidence witnessing the presence of other-regarding (social) preferences. The suggested rationale is that in the social relations in which the two players are involved embed a disposition to trust by the sender and the expectation of trustworthy behaviour by the responder. When each player's behaviour conforms to altruism the maximization of the utility function of the two players depends on the sum of their respective payoffs (Rabin, 1993); when it conforms to inequality aversion consists in the minimal distance between their respective payoffs (Fehr and 
Schmidt, 1999; Bolton and Ockenfels, 2000). Still, we are convinced that this is by no means the full story. To sustain our doubts, the typical example is the sequential Prisoner's Dilemma (PD), where it is difficult to tell whether cooperative behaviour is the effect of reciprocity or of altruism. Therefore, the motivation for the trusting and/or the reciprocating behaviour delivering the cooperative solution in one-shot games with conflict of interest deserves a more comprehensive investigation.

In the literature following the seminal paper in which Glaeser et al. (2000) elaborated measures of self-reported trust and trustworthiness (answers to questionnaires such as the World Value Survey (WVS) and the European Social Values (ESV)), the question has been posed to what extent there could be a connection between attitudes to trust and trustworthiness and actual behaviour observed in laboratory experiments. ${ }^{1}$ The correlation between the disposition towards trust and reciprocation declared in the questionnaire of the World Value Survey (WVS) or the European Value Survey (EVS) and the findings of experiments testing the actual behaviour in Trust Games is presently highly debated. Attitudinal survey questions as reported in the EVS are often regarded as inefficient indicators of trust, since they lack behavioural underpinnings (Putnam, 1995), as one might desire when measuring trust. Glaeser et al. (2000) was the first to compare attitudinal and behavioural evidence stemming from experiments, reporting that attitudinal survey questions do not predict trusting behaviour in experiments. Lazzarini et al. (2005) presents similar experimental evidence. Glaeser et al. (2000) and Sapienza et al. (2007) find a correlation between attitudinal trust and behavioural evidence of expected trustworthiness, which does not show up in the results put forward by Fehr et al. (2003). A possible explanation proposed by Sapienza et al. (2007) who notes the peculiarity of this latter experimental evidence, where heterogeneity across German households as players in the TG impedes the trustor from identifying himself with the trustee, thus causing a deviation of the experimental evidence from the WVS's attitudinal evidence.

However, many papers (most notably Charness and Rabin, 2005 and Cox, 2004) have lamented the lack of a clear distinction between the behavioural trust and reciprocity manifested by, respectively, the first and second movers in Trust Game experiments. Indeed, the players' intentions are revealed by the matrix of the monetary payoffs and their distribution, as happens in the accounts of trust and reciprocity in which only the distributive outcome matter (Bolton and Ockenfels, 2000; Fehr and Schmidt, 1999). Provided that the first mover in a Trust Game in extensive form waives the Nash play of sending zero, two different designs of the game elicit different motives. If an outside option

\footnotetext{
${ }^{1}$ It was contended that the degree of trustworthiness of the social context in which individuals operate may interfere with individuals' trust. The most frequent criticisms are: (i) the tendency to set up an hypothetical situation in responding to a questionnaire could lead the subject to underlook possible threats just because he does not find himself in a real setting; (ii) the tendency to self-idealisation, so that the subject may overestimate his standing in terms of moral values; (iii) the lack of a gain may induce the subject to give loose answers (see, for instance, Ciriolo, 2007).
} 
is inserted in the extensive form, a first mover who discards this option and sends a certain amount to the second player makes a "voluntary" choice of "investing" in the relationship, while the first player's choice in the traditional design can be labelled "involuntary" (McCabe, et al., 2003). Similarly to the first mover of the Rosenthal's (1981) Centipede, the trustor reveals the intention to bear a risk (to get a payoff lower than the outside option) and the trustee may then be moved by a sentiment of reciprocation (and also of gratefulness, as his self-esteem is strengthened by the other player's recognition of his trustworthiness).

The intention to "invest" in the Trust Game in extensive form revealed by a move could conceal different motivations. Whether the motive hidden beneath the manifest behaviour of the first mover is the desire to invest in a relationship of mutual advantage with the trustee or the desire to be good to him independently from his own final payoff, remains an unsettled question. The question then is how to identify the motive which is actually at work, out of the two possible motives embedded in the trust game: 1) an "investment" motive - conditional cooperation is a way to express the expectation of reciprocal behaviour; and/or, 2) an altruistic motive - what may appear as an "investment" actually conceals a social preferences, that is the intention to gratuitously favour the other player.

In this paper we attempt to elicit the true motive underlying the behaviour of each of the two players and suggest that the most informative utilization of surveys in this regard goes beyond the simple comparison between answers to a questionnaire and actual behaviour. The statistical treatment of players' behaviour in the sessions, by means of attitudes as shown by their answers, allows a deeper understanding of the players' behaviour and a better evaluation of the experimental results. Therefore, the objective of disentangling the strategic motive (the intention of the trustor to elicit benevolence from the trustee, and the trustee interest in reciprocating) from the altruistic motive will be pursued by establishing a correlation between the attitudinal and the behavioural measures of trust and trustworthiness. In this paper, we will then be using the "words" of answers to a questionnaire in order to more deeply understand the motivations behind "actions". 


\section{Model 1. The standard Trust Game experimental design}

The first question we address here is the replication, in an Italian environment, of the same experimental design implemented by Glaeser et al. (2000) for the United States and Lazzarini et al. (2005) for Brazil, in order to test the relationship between the two players' behaviour and the questionnaire answers. These sessions were conducted in Siena and Salerno, in May and July 2007. Overall, 168 students participated in the sessions of this first part of the experiment.

All sessions were divided into two different stages. In the first stage, the subjects were asked to fill in a questionnaire in which some of the EVS questions were reproduced (X out of Y). As observed by Glaeser et al. (2000), any measure of trust is likely to also be a measure of trustworthiness. Furthermore, recent experimental research (Fehr and Schimdt, 2001, 2005) indicates that trust and trustworthiness can hardly be disentangled, since individuals tend to reciprocate and to respond to the social behaviour they observe in real life contexts. ${ }^{2}$ Although surveys tend to sharply differentiate between the questions referring to trust and those referring to trustworthiness, trust and trustworthiness may be interwoven even within each agent, as the level of trust manifested by of each agent is moulded by his own life experience of the degree of trustworthiness of individuals belonging to his social environment. ${ }^{3}$

We then asked all subjects - those who played as senders and those who played as Respondents to answer both the standard questions from the World Values Survey eliciting the general level of trust of the subject ("Generally speaking, would you say that most people can be trusted, or that you can never be too careful when dealing with others?" (v47), and "Do you think that most people would try to take advantage of you..." (v23)), as well as some more specific question (do you think that it is important.... to say the truth, to pay the ticket on the bus), eliciting the opinion of the subject about compliance to civic virtues in his social environment, as a proxy of his degree of trustworthiness. Therefore, in addition to basic information on the characteristics of subjects, the questionnaire gathers information on what may be called the two subject's selves: (i) his personal self, that is his personal opinion about the degree to which people in their environment and/or political institutions could be trusted; (ii) his social self, that is the civic virtues he feel like to comply (or not comply) with as an individual belonging to his social environment; indeed, his

\footnotetext{
${ }^{2}$ In the words of Bacharach, Guerra, and Zizzo (2001), “(o)nce it can be shown that it is reasonable to expect trustworthiness there is no longer any mystery about trust, since trust is typically a best reply to this expectation" (Ibidem, pp.1-2).

${ }^{3}$ However, the question is far from being settled. Under the opinion that trust and trustworthiness, being different components of the individuals' utility functions, are to be separately considered, the trusting behaviour has been defined "as the combination of the beliefs in other people's trustworthiness and the specific preferences of the sender (risk aversion, reciprocity, altruism)" (Sapienza et al., 2007, p.3).
} 
evaluation of the degree of trustworthiness that a particular social situation merited has to be taken as a proxy of the degree in which he could be considered trustworthy. The rationale is that the more a subject can be considered trustworthy, the more others can expect reciprocity from him. The Appendix reports the complete set of trust/trustworthy questions that appeared on the students' computer screens.

The criteria we followed in selecting these specific questions are related to our hypotheses testing. In fact, we concentrated our attention on the set of questions which are aimed at assessing the individual's level of trust and trustworthiness, together with some general characteristics which, in past research work, have proved to be influential as far as trusting behaviour is concerned.

As for the second stage, as in previous analyses of behavioural trust, we adopted the experimental setting of the Trust (Investment) Game (Berg et al. 1995). This game involves a bargaining context in which two players (Senders and Respondents) decide how to share a well defined amount of money ${ }^{4}$. At the first step, Senders make an investment decision transferring a certain number of experimental tokens to Respondents. The number of tokens is then tripled by the experimenter, so that Respondents receive three times the amount of tokens initially sent. At the second step, Respondents decide how many tokens return back to Senders. The standard design was adopted, in as much as subjects were randomly divided into two groups (Respondents and Senders) once they had completed the questionnaire, and then the game was played according to the rules described above.

There are three main differences between our work and those of Glaeser et al, 2000 and Lazzarini et $a l, 2005$. First, we set the multiplying factor $-\alpha$ - equal to 3 , as in the original design by Berg et al. (1995), rather than 2, as in the two above mentioned papers. The reason is that the higher value of $\alpha$ coefficient places a high weight on trustworthiness, which can then be better monitored. Second, differently from Lazzarini et al. (2005), where subjects were playing in face-to-face interactions, Senders and Respondents were selected randomly and anonymously by the computer and no personal communication was allowed during the sessions. ${ }^{5}$ Third, we adopted the anonymous partnership protocol as we wanted to avoid that any previous information effect shared by the subjects could affect results. To preserve comparison with the Trust Game experiments conducted in very different cultural and social environments such as the United States and Brazil, any disturbances due to the interplay between attitudes resulting from particular cultural values and behaviour induced by the specific experimental setting had to be minimized. All these features of the

\footnotetext{
${ }^{4}$ The Sender initial endowment was equal to 10 experimental tokens. The experimental exchange rate was set to 0.1 Euro cent for each token. Payoffs varied between 6 and 10 Euro per subjects. Details of the payoff structure were illustrated in he Instruction sheet.

${ }^{5}$ In Glaeser et al., 2000, friends were allowed to participate in the same trust game. The effect of friendship or, more generally, of a previous social relationship on trusting behaviour was however unclear.
} 
experimental design were used in both Model 1 and Model 2. An additional feature was introduced in Model 2, whereby not only the first but also the second mover was endowed with 10 tokens.

\section{Model 1. A comparison between attitudinal and behavioural measures}

Table 1 presents the results of estimating Model 1: Ordered Probit regressions connecting behaviour in the Trust Game to answers to questions concerning each agent's self-evaluation of his trusting attitude as a person and of being trustworthy as a participant in his social environment. More specifically, we test: (i) the correlation between the Sender's trust EVS questions (his own personal characteristics and opinion in evaluating institutions) and his behavioural trust measure (the amount sent); (ii) the correlation between the Responder's EVS trustworthiness questions and his behavioural trustworthiness (the amount sent back).

Table 1: Model 1 Ordered Probit model of amounts sent and sent back

\begin{tabular}{|c|c|c|c|c|c|c|c|c|}
\hline & \multicolumn{4}{|c|}{ Senders: Tokens sent } & \multicolumn{4}{|c|}{ Recipients: Tokens sentback } \\
\hline & \multicolumn{2}{|c|}{ Full model } & \multicolumn{2}{|c|}{ Only V47 } & \multicolumn{2}{|c|}{ Full model } & \multicolumn{2}{|c|}{ Only V47 } \\
\hline & Coef. & $\mathrm{z}$ & Coef. & $\mathrm{z}$ & Coef. & . $\mathrm{Z}$ & Coef. & . $\mathrm{Z}$ \\
\hline Tokens sent & - & - & - & - & 0.62 & 8.09 & 0.56 & 9.07 \\
\hline salerno & 0.32 & 1.03 & 0.35 & 1.29 & 0.08 & 0.23 & 0.13 & 0.49 \\
\hline Female & -0.14 & -0.49 & -0.64 & -2.79 & 0.19 & 0.62 & 0.23 & 0.96 \\
\hline age & 2.35 & 1.70 & 1.89 & 1.52 & -1.89 & -1.19 & -0.17 & -0.14 \\
\hline Mid to high income family & -0.11 & -0.31 & -0.08 & -0.30 & 0.32 & 0.82 & 0.22 & 0.73 \\
\hline Economics student & -0.04 & -0.15 & -0.06 & -0.26 & -0.36 & -1.14 & -0.49 & -2.02 \\
\hline Mother has secondary or tertiary education & 0.21 & 0.81 & 0.20 & 0.91 & 0.36 & 1.24 & 0.39 & 1.62 \\
\hline Index of trust (v47) & 0.37 & 1.65 & 0.48 & 2.64 & -0.71 & -2.24 & -0.31 & -1.36 \\
\hline Trust the family & 0.38 & 1.06 & - & - & 0.45 & 0.97 & - & - \\
\hline Trust people you know & 0.31 & 0.69 & - & - & -0.63 & -1.50 & - & - \\
\hline Trust new aquaintances & 0.24 & 0.61 & - & - & 0.36 & 0.87 & - & - \\
\hline Trust immigrants & 0.02 & 0.07 & - & - & 0.45 & 1.16 & - & - \\
\hline Trust the government & -0.10 & -0.28 & - & - & -0.21 & -0.55 & - & - \\
\hline Trust Parliament & -0.27 & -0.74 & - & - & -0.50 & -1.36 & - & - \\
\hline Trust Political Parties & 0.98 & 1.88 & - & - & 0.58 & 1.23 & - & - \\
\hline Trust Public Officials & -0.23 & -0.71 & - & - & 0.21 & 0.54 & - & - \\
\hline \multicolumn{9}{|l|}{ It is Justified to: (1=never; $10=$ always) } \\
\hline Try to obtain State benefits ilicitly & -0.23 & -1.27 & - & - & -0.30 & -1.43 & - & - \\
\hline Evade taxes & 0.15 & 0.62 & - & - & 0.37 & 1.79 & - & - \\
\hline Drive someone else's car without their perr & 0.47 & 2.40 & - & - & -0.09 & -0.44 & - & - \\
\hline Tell lies in one's own interests & 0.39 & 2.05 & - & - & 0.39 & 1.93 & - & - \\
\hline for someone to have an extra marital affair & -0.03 & -0.21 & - & - & 0.15 & 0.80 & - & - \\
\hline \begin{tabular}{|l|l} 
Accept illegal payments (bribes) \\
\end{tabular} & 0.09 & 0.40 & - & - & 0.04 & 0.20 & - & - \\
\hline Use moonlighters - to avoid taxes & -0.22 & -0.88 & - & - & -0.06 & -0.27 & - & - \\
\hline Ride on the buses without paying & -0.16 & -0.85 & - & - & -0.48 & -2.21 & - & - \\
\hline n & \multicolumn{2}{|c|}{91} & \multicolumn{2}{|c|}{92} & \multicolumn{2}{|c|}{83} & \multicolumn{2}{|c|}{88} \\
\hline Pseudo R-Squared & \multicolumn{2}{|c|}{0.10} & \multicolumn{2}{|c|}{0.05} & \multicolumn{2}{|c|}{0.29} & \multicolumn{2}{|c|}{0.25} \\
\hline
\end{tabular}

note: coefficients which are significant at $.05<\mathrm{p}<.10$ are indicated in italics, coefficients which are significant at $\mathrm{p}<.05$ are indicated in bold. 
Answers to the "Trust question" (v47) present for Senders the right sign and the coefficient is significant at $10 \%$. As for the Respondents, the negative sign on the coefficient is significant at $5 \%$ however the economic meaning is, to say the least, a little strange, as it would imply that the more he trusts, the less he sends back.

As for the other questions, the Senders manifest a sort of "manipulative behaviour", as the higher their score on questions such as it being justified to lie in one's own interests or to take your friend's car without permission, etc., show a moral acceptance of cheating, the more they send. On the other hand, for Respondents the more they demonstrate a moral acceptance of lack of civic values and, in particular, literally free-riding behaviour (i.e. to travel on the bus without ticket), the less money they send back. The implication is that both Senders and Respondents are eager to take advantage of any opponent's positive attitude to make business, even in spite of their tendency to downplay anti-civic behaviour as reported by the declared opinions "about the others". On the one hand, the first disregards any moral evaluation of the second mover since the lower is the latter's moral intransigence the more he invests. A plausible reason is the expectation that the disposition to cooperate in a strategic interaction is not reduced, but possibly magnified, by proneness to collusive behaviour as shown by the second mover's answers. On the other hand, the second player appears to be encouraged to put in place a "saving behaviour" (he may think: "the less you send me, the less you deserve me to be sent you back"), which we can consider "soft reciprocity", that is a social disposition to the punishment of the free-rider but at a personal benefit.

Therefore, our replication in Model 1 of the standard Trust Game experimental design in order to test the relationship between the two players' behaviour and the questionnaire answers by Ordered Probit produced opaque results. In contrast to Glaeser et al. (2000) and to Sapienza et al. (2007), we find no correlation between attitudinal trust and behavioural trustworthiness. Similarly to Fehr et al. (2003), attitudinal trust appears to only moderately entertain a certain degree of correlation with behavioural trust. All in all, the presumption that answers to a survey predict behaviour in laboratory experiments is then initially rejected.

What we can say for now, in interpreting the results obtained with Model 1 is that both players, whatever is their own opinion about trust in their social environment, are oriented to rely on their permissive judgement about the others' disposition to civic cooperation with the intention to get the most from strategic interaction. 


\section{Model 2. Searching for the real motive underlying behavioural trust and reciprocity}

An experimental design in which the positive reciprocal behaviour responding to a generous action is neatly separated out from other-regarding (social) preferences has been constructed by Cox (2004). Cox modified the well-known investment game by Berg, Dickhaut and McCabe (1995) in order to obtain information on whether it is the "trust/reciprocity" motive or the "social preference" motive which underlies players' behaviour. We drew on the 'Cox' experimental design to conduct a second set of experimental sessions in December 2007, the subjects being undergraduate students at the University of Siena. The students were randomly divided in two groups (Senders and Respondents, respectively), and each of them was denoted by the number of the computer and the number of the session in which he seated. As before, and in contrast to Glaeser et al. (2000) and Lazzarini et al. (2005), the double-blind procedure, that is anonymity with respect to both the other player and the experimenter, was insured. ${ }^{6}$

The so-called "triadic" design by Cox comprises three treatments: 1) a Trust (Investment) Game (TG), in which both the senders and the Respondents were endowed with ten tokens (the rate of change was 1 token $=$ euro); the trustees had to decide whether to send back some, all, or part of his endowment; 2) a Dictator Game (DG1), in which the trustor has to decide whether to send or not to send (all, or part of) his endowment to the other player - in the Instructions, both players were informed that the sender would by no means have had the opportunity to interact with the other player, as this latter player had to remain passive; and, 3) a modified Dictator Game (DG2), in which a second mover acting as Respondent had to send back or not to send back (all, or part of) the amount that he has received by a first-mover acting as sender ${ }^{7}$, which the experimenter had multiplied by three. In the Instructions for DG2, the Respondent is made aware that the amount received was sent not by his opponent in the game he was playing, but by another unknown player whom he would not have had the opportunity to interact with. A number of players was 33 pairs in the first two treatments and 31 pairs in the last one. In order to preserve independence in behaviour, each subject participated in only one session.

The subjects were also asked to fill out the same questionnaire used in Model 1. Coherently with the arguments presented in section 2, we do not follow Cox (2004) in differentiating questions between

\footnotetext{
${ }^{6}$ In the IMBE Conference held Alicante in February 2008, where a shorter version of this paper was presented, another paper dealing with attitudinal and behavioural measures of trust and trustworthiness was delivered (see in the references Capra et al., 2008). However, no comparison can be made, as the design of this paper does not use the double-blind precedure and the same subjects participate in all games.

${ }^{7}$ Which could of course also be zero.
} 
the two groups of players. In fact, we do not think to be appropriate to distinguish between the opinion of the subject when he is playing as a Sender and when he is playing as a Respondent. As will be understood from the following, the elicitation of trustors' opinions about the others' degree of trustworthiness allows us to deepen our understanding about the motive(s) underlying the "high" or "low" amount they have sent. Similarly, to elicit trustees' attitudes to trust (in addition to information on their degree of trustworthiness) allows us to deepen our understanding about the motivation underlying the amount they returned.

Table 2: Model 2 Ordered Probit ‘Cox’ model of amounts sent and sent back

\begin{tabular}{|c|c|c|c|c|c|c|c|c|}
\hline \multirow{3}{*}{\begin{tabular}{|l|} 
\\
Tokens sent \\
\end{tabular}} & \multicolumn{4}{|c|}{ Senders: Tokens sent } & \multicolumn{4}{|c|}{ Recipients: Tokens sentback } \\
\hline & \multicolumn{2}{|c|}{ Full model } & \multicolumn{2}{|c|}{ Only V47 } & \multicolumn{2}{|c|}{ Full model } & \multicolumn{2}{|c|}{ Only V47 } \\
\hline & - & - & - & - & 0.34 & 4.73 & 0.24 & 3.90 \\
\hline DG1 & -0.18 & -0.58 & -0.23 & -0.89 & -0.51 & -1.67 & -0.10 & -0.35 \\
\hline Female & -0.57 & -1.52 & -0.37 & -1.19 & -0.33 & -0.89 & 0.05 & 0.20 \\
\hline age & -7.78 & -3.45 & -5.38 & -2.83 & -4.94 & -1.97 & -4.18 & -2.06 \\
\hline Mid to high income family & -0.46 & -1.39 & 0.06 & 0.23 & 0.07 & 0.22 & 0.20 & 0.76 \\
\hline Economics student & -1.46 & -2.50 & -0.73 & -1.47 & \begin{tabular}{l|l}
-1.11 \\
\end{tabular} & -1.76 & -0.59 & -1.14 \\
\hline Mother has secondary or tertiary education & -0.27 & -0.81 & -0.45 & -1.66 & -0.04 & -0.12 & -0.02 & -0.06 \\
\hline Index of trust (v47) & -0.44 & -1.17 & 0.00 & -0.01 & -0.13 & -0.44 & 0.05 & 0.20 \\
\hline Trust the family & 0.89 & 1.74 & - & - & -0.11 & -0.26 & - & - \\
\hline Trust people you know & 0.57 & 1.26 & - & - & 0.23 & 0.41 & - & - \\
\hline Trust new aquaintances & 1.09 & 2.22 & - & - & 0.49 & 0.96 & - & - \\
\hline Trust immigrants & -0.63 & -1.79 & - & - & -0.43 & -0.93 & - & - \\
\hline Trust the government & 0.40 & 0.97 & - & - & -0.33 & -0.76 & - & - \\
\hline Trust Parliament & 0.38 & 0.94 & - & - & 0.85 & 1.79 & - & - \\
\hline Trust Political Parties & -0.54 & -1.34 & - & - & 0.50 & 0.66 & - & - \\
\hline Trust Public Officials & 0.24 & 0.74 & - & - & -0.57 & -1.24 & - & - \\
\hline \multicolumn{9}{|l|}{ It is Justified to: $(1=$ never; $10=$ always $)$} \\
\hline Try to obtain State benefits ilicitly & 0.10 & 0.33 & - & - & 0.28 & 1.12 & - & - \\
\hline Evade taxes & -0.14 & -0.41 & - & - & 0.09 & 0.37 & - & - \\
\hline Drive someone else's car without their permi & 0.60 & 2.47 & - & - & 0.19 & 0.78 & - & - \\
\hline Tell lies in one's own interests & 0.09 & 0.29 & - & - & 0.44 & 1.32 & - & - \\
\hline for someone to have an extra marital affair & 0.10 & 0.49 & - & - & 0.41 & 1.87 & - & - \\
\hline Accept illegal payments (bribes) & 0.13 & 0.52 & - & - & -0.51 & -1.98 & - & - \\
\hline Use moonlighters - to avoid taxes & 0.01 & 0.03 & - & - & -0.33 & -1.02 & - & - \\
\hline Ride on the buses without paying & -0.25 & -0.85 & - & - & \begin{tabular}{l|l}
-0.46 \\
\end{tabular} & -1.81 & - & - \\
\hline $\mathrm{n}$ & \multicolumn{2}{|c|}{66} & \multicolumn{2}{|c|}{66} & \multicolumn{2}{|c|}{66} & \multicolumn{2}{|c|}{66} \\
\hline Pseudo R-Squared & \multicolumn{2}{|c|}{0.13} & \multicolumn{2}{|c|}{0.05} & \multicolumn{2}{|c|}{0.12} & \multicolumn{2}{|c|}{0.05} \\
\hline
\end{tabular}

note: coefficients which are significant at $.05<\mathrm{p}<.10$ are indicated in italics, coefficients which are significant at $\mathrm{p}<.05$ are indicated in bold.

In Model 2 (Table 2), the correlation between the general trust question (v47) and the amount sent and returned present a negative sign both with the Respondents' and the Senders' answers - for trusting participants there is even less tendency than in Model 1 to send or send back more than others. Moreover, personal characteristics (such as age and being an economics student) negatively 
impinge on generosity in sending. In general, questions dealing with the subject's opinion about the others' civic values perform similarly to results in Model 1.

When individuals are ranked according to the amounts sent and received back in each treatment, we are in the position to disentangle the individuals' disposition towards trust and reciprocity by comparing the behaviour determined by social preferences in the non-strategic interaction of treatments 2 and 3 with the strategic setting in which the two players are posited in the TG. The sender's strategic behaviour in the TG results from the comparison of the amount sent by the trustor in the TG with the other-regarding preferences exhibited by the analogous player in the DG1 setting free from strategic considerations (figures $1 \& 2$ ). Similarly, a measure of the responder's reciprocating behaviour results from the comparison between the responder's strategic behaviour in the TG and the other-regarding preferences exhibited by the analogous player in the DG2 setting free from strategic considerations (figure 2).

Figure 1: Amounts sent, 'Cox' type TG and DG1 designs, by paired players

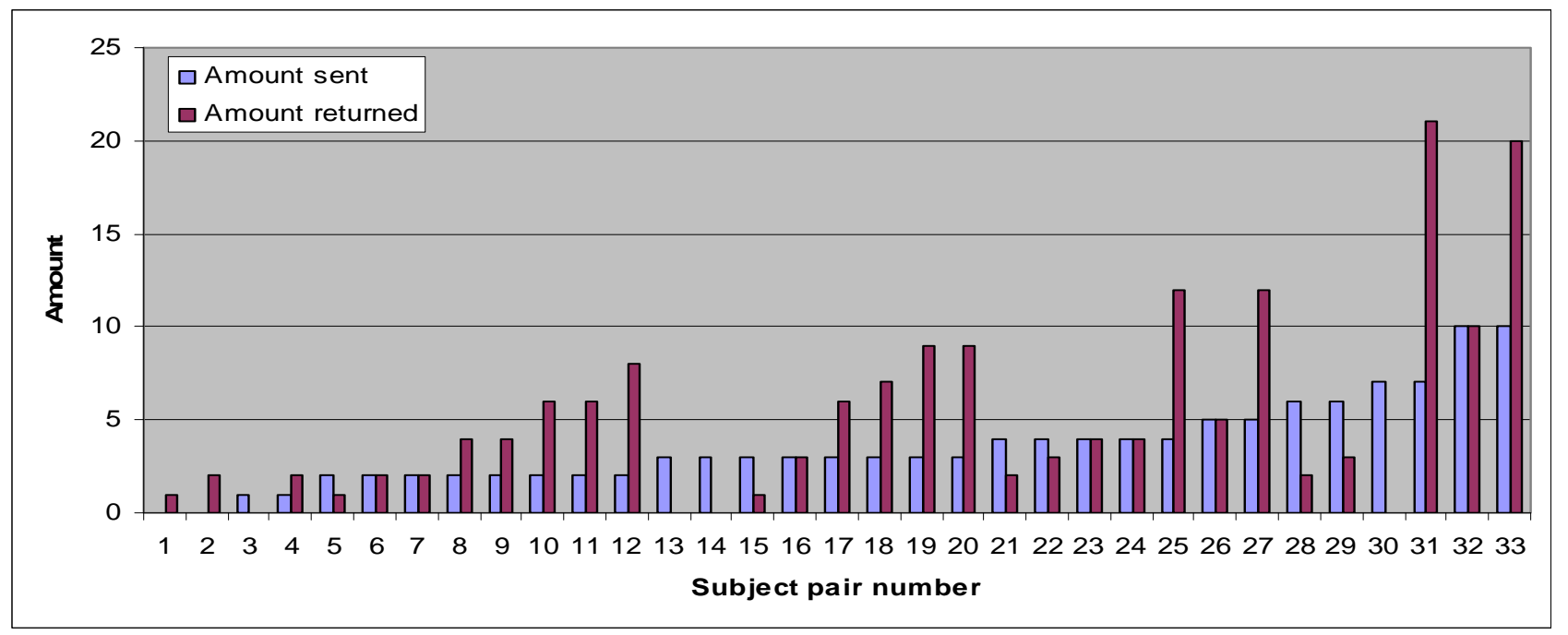


Figure 2: Amounts sent, 'Cox' type TG and DG1 designs, frequencies

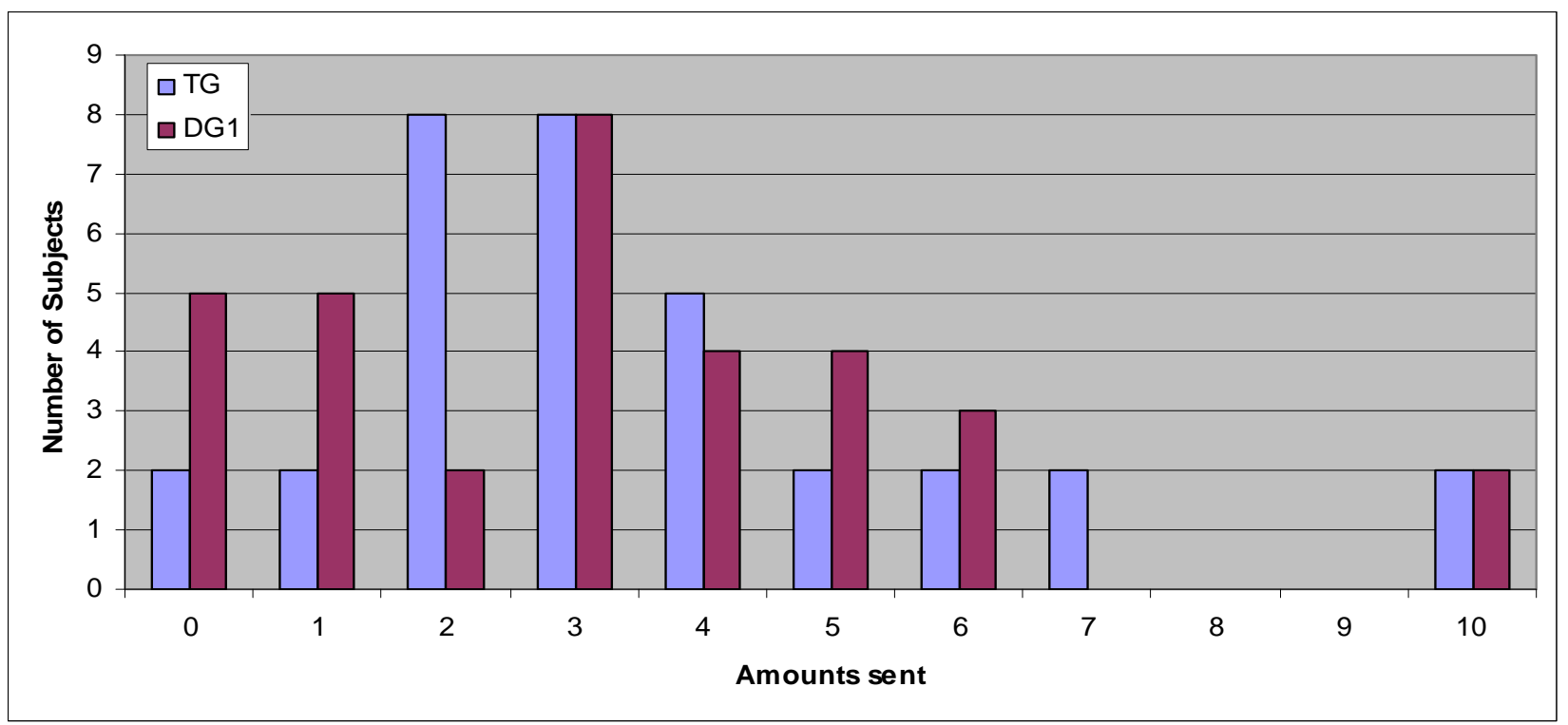

Figure 3: Amounts returned 'Cox' type TG and DG2 designs, by paired players

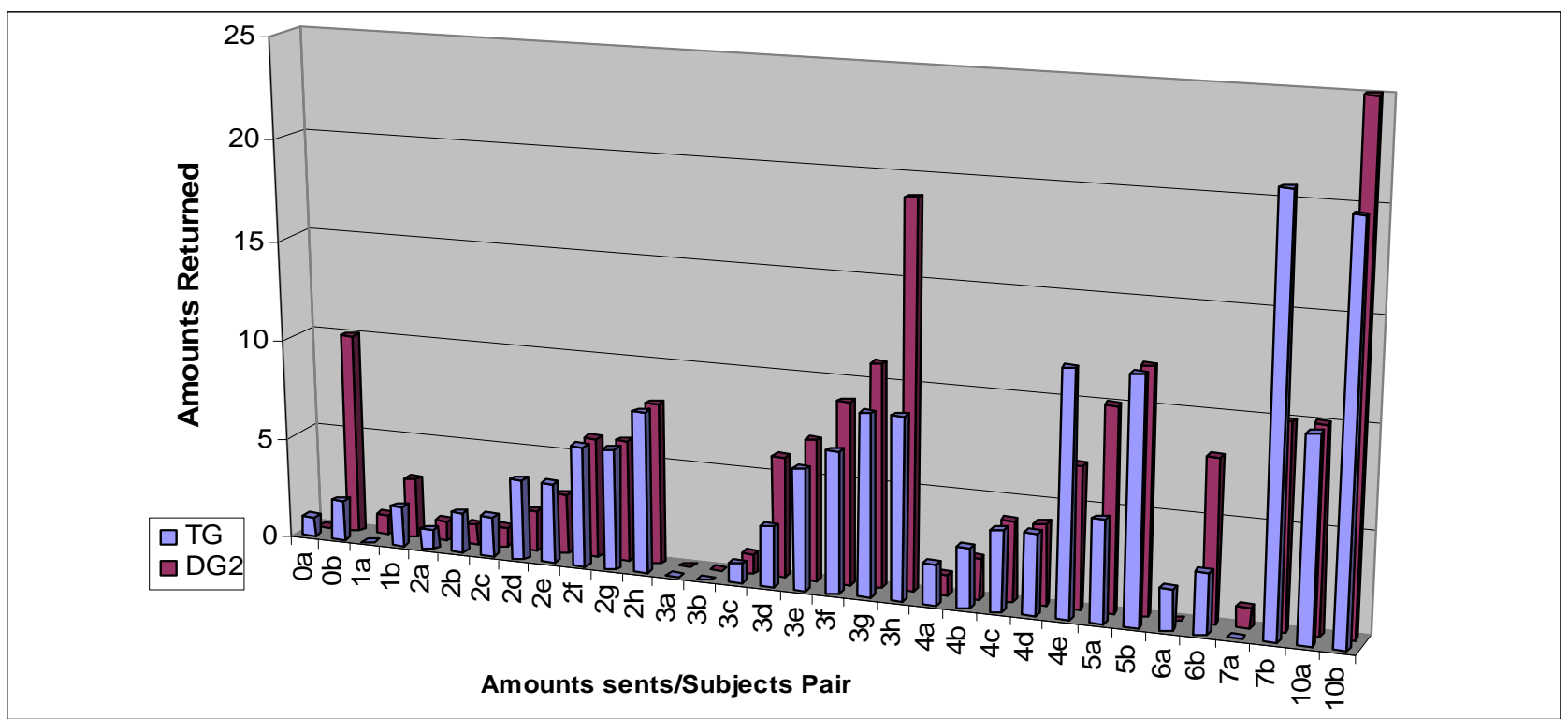


The comparison of the results of the TG with the DG1 ones allows us to infer a measure of the sender's possible trusting behaviour (figure 1). On average, the amount sent in the TG is greater than the amount sent in the DG1 (figure 2), and the amount sent back in the TG is lower than the amount sent in the DG2 (figure 3). In the latter figure, the blue bars show the amount sent back in the TG and the red bars show the amount sent back in the DG2. In general, the subjects playing as first movers send amounts lower than in the experimental sessions performed by Cox. On the one hand, differently from Cox's results the amount sent by the trustor is positive in almost all cases (the ratio of a positive amount sent is $31 / 33$ vis-à-vis 26/32), and a zero amount sent is much less frequent than in the Cox one (we obtain a zero return two times in TG and five times in DG1 vis-àvis 6 in TG and 11 in DG1 in the Cox sessions). On the other hand, the frequencies of players of the TG are much higher at the low than at high levels of amount sent, compared to the Cox sessions (the number of first movers who send less than 5 tokens is 23 vis-à-vis 4; the number of first movers who send all the 10 tokens is only 2 vis-à-vis 13). As for the second movers, while zero return happens only 4 times vis-à-vis 9 times in Cox's experiment, the trustee send back on average a lower amount than in the Cox sessions. Considering the low amount sent on average by the trustees, this result is probably also a consequence of a scant disposition to reciprocate. We will take back this argument later on.

Overall, by comparing the TG and the DG1 and the TG and the DG2, respectively, the inclination towards strategic reasoning stands out more clearly in our experiment than in Cox's one. As for senders, in common with Cox we find that the amount sent in TG is in excess with respect to DG1, but on average with lower values than in his experiment (the mean amount sent in our experiment was $\$ 3.58$ in the TG and \$3.24 in the DG1, whereas it was \$5.97 in TG and \$3.63 in the Cox's experiment). As for respondents, the same result applies, as the average amount returned in our experiment was $\$ 1.50$ and $\$ 1.64$, compared to $\$ 4.94$ and $\$ 2.06$, respectively, in Cox's one.

These differences can be subjected to a more rigorous test. Following Cox (2004), we implement a test to statistically distinguish between the amounts sent in trust and dictator games. Formally, the general structure of the model estimated is:

$$
\mathrm{R}_{\mathrm{i}}=\alpha+\beta \mathrm{D}_{\mathrm{i}} \mathrm{S}_{\mathrm{i}}+\gamma \mathrm{S}_{\mathrm{i}}+\varepsilon_{\mathrm{i}}
$$

Where $R_{i}$ is the amount sent back, $S_{i}$ the amount received by the recipient and $D_{i}$ is a dummy taking the value of 1 for the trust game participants. The coefficients $\beta$ and $\gamma$ provide the means to distinguish between reciprocation and 'other-regarding' preferences. Since, as noted above, in the (modified) dictator game (DG2) there can be no reciprocating motive, the difference between the 
reaction of respondents to the amount sent in the two settings $(D=0$ and $D=1)$ is a measure of pure reciprocity, specifically, the $\beta$ coefficient.

As to the specific technique employed for the estimation, as above, we prefer an ordered probit model to implement the test rather than the two-limit tobit model with heteroskedasticity correction used by Cox. It is true that the amounts to be sent back are bounded but this doesn't seem to us to

Table 3: Ordered probit model of 'Cox' type test of difference in amounts sent back in trust and dictator games.

\begin{tabular}{|c|c|c|c|c|c|c|}
\hline \multirow[t]{3}{*}{ Cox Test } & \multicolumn{3}{|c|}{ 2nd experiment } & \multicolumn{3}{|c|}{ 1st \& 2nd experiment } \\
\hline & Coef. & & & Coef. & & $\mathrm{z}$ \\
\hline & 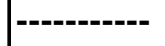 & & & --.-- & & -..- \\
\hline Beta & & -0.01 & -0.23 & & -0.04 & -0.81 \\
\hline Gamma & & 0.21 & 3.28 & & 0.35 & 6.33 \\
\hline n & & 66 & & & 158 & \\
\hline $\mathrm{R}-\mathrm{sq}$ & & 0.04 & & & 0.09 & \\
\hline
\end{tabular}

be the significant issue in the econometrics here. The ordered probit model does not impose a priori that the marginal effects in the model are constant across amounts sent back moreover, as is well known, the implementation of a parametric heteroskedasticity correction term as in Cox (2004) is subject to the objection that the 'correction' is actually picking up a substantive effect (see, for example, Davidson \& MacKinnon, 1986). Our results (reported in Table 4) show that there is no statistical distinction to be made between trust and dictator games in terms of the amounts sent back. In contrast to Cox's results, the amount sent back is positive and statistically significant - for both trust and dictator games. However, the estimated effect of the amounts sent $(\gamma)$ increases when observations from the earlier trust experiment are added. Once the strategic setting reflecting reciprocity is considered, an impressive improvement in the correlation between amount sent and amount sent back shows up. This suggests that statistical analysis of the information conveyed by the questionnaire may provide further insight into what is actually going on. The following section takes this up with the aim of identifying subjects' underlying motives by matching their selfdeclared attitudes with their behaviour. 


\section{Using attitudinal measures to control for motivation}

In this section we offer a way of putting together behavioural and attitudinal measures in such a way that provides a coherent explanation for the results outlined above as well as offering further insight into what is actually going on. By using the attitudinal questions, participants were identified as trusting or prudent on the one hand and trustworthy or untrustworthy on the other. Players with a value of the trust index (V47) above the median ( $=5$ as it happens) were defined as trusting and others prudent; similarly, a composite index of trustworthiness was constructed from the answers to the relevant questions ${ }^{8}$. Those with values above the median $(=22)$ were defined as untrustworthy, others $(\leq 22)$ were defined as trustworthy. It is worth observing that there was no correlation in our sample (both overall and for each experiment separately) between trusting and trustworthy individuals as defined here. Table 4 reports the mean amounts sent and the mean return ratio overall, and separately for the two sample divisions - trusting/prudent and trustworthy/untrustworthy.

In analysing the results we will test our hypothesis whereby the declared attitude towards trust reflects the self-perception about the participants' own propensity to trust people and the declared attitude towards trustworthiness reflects the own evaluation of the civic virtues of others.

Comparing trusting and prudent individuals, one may observe that in the trust (investment) game, trusting individuals in the role of first movers, send much more (mean $=4.4$ ) than prudent individuals (mean $=2.9$ ) as one might expect. When playing the dictator game, however, trusting and prudent first movers send approximately the same amounts on average. Looking at the trustworthy/untrustworthy divide, amounts sent in the trust game is virtually the same for the two groups of individual (3.50 for the trustworthy group and 3.63, actually a little more, for the untrustworthy group). In the dictator game there is a modest difference between the trustworthy (mean tokens sent $=3.44)$ and the untrustworthy (mean $=3.00)$. What is striking is that the "trustworthy" send less than the "trusting". This result seems to confirm that the propensity to send depends more on the expected reciprocal behaviour by others which in turn is influenced by the trusting nature of the participants, rather than on some sense of fairness or other-regarding preferences manifest in the civic nature of players. Another indirect proof of this behaviour is that trusting individuals and - to a lesser extent - trustworthy individuals "invest" in the interaction of the trust game more than in the DG1, where no strategic reasoning applies. Overall, considering the two groupings together, we may conclude that in a setting of strategic interaction such as the TG the

\footnotetext{
${ }^{8}$ Specifically, the index is the simple sum of responses to the questions of the form: Is it (from never $=1$ to always $=10$ ) justified to...e.g. evade taxes and so on. The resulting index covers the full possible range (from 8 to 80 ) with median $=22$. It might be more appropriate to think of this index more in terms of civic sense, rather than trustworthiness per se.
} 
personal disposition to send money to the other player matters more than the moral opinion about the people with whom you are going to interact.

As for respondents, the general presumption is confirmed that for the reciprocating behaviour matter both the self-evaluation of one's own disposition to trust and the evaluation about the civic virtues of others. Yet, some more profound insights emerge, as strategic interaction appears to draw out conditional cooperation. Comparing the amount returned in the modified dictator game (DG2) and in the TG, the first divide presents little difference between the return ratio of the two groups, but trusting individuals return a smaller proportion of the amounts received than do prudent individuals. We would suggest that this result is evidence of strong reciprocity, in the sense that the "trusting" feel betrayed by the other player and react by returning a small amount. Data become even more telling by taking into account also the second divide. The mean return ratio for trusting and prudent, respectively, were 1.61 and 1.45 (TG) and 1.76 and 1.55 (DG2), but nearly 70\% higher for "trustworthy" (1.84) than for "untrustworthy" individuals (1.10)). Thus, the trusting and - to a much larger extent - the trustworthy individuals send back in the trust game a larger amount than the prudent and the untrustworthy individuals, respectively.

Table 4: 'Cox' - type experiments, mean amounts sent and mean return ratio by attitudinal trust and trustworthiness

\begin{tabular}{|lc|cc|cc|}
\hline & & Mean & & Mean & \\
& Sokens & & return & \\
Ratio & N \\
\hline All & TG & 3.58 & 33 & 1.50 & 31 \\
& DG1 & 3.24 & 33 & - & - \\
& DG2 & - & - & 1.64 & 31 \\
\hline Trusting & TG & 4.40 & 15 & 1.61 & 11 \\
& DG1 & 3.08 & 12 & - & - \\
& DG2 & - & - & 1.76 & 14 \\
\hline Prudent & TG & 2.89 & 18 & 1.45 & 20 \\
& DG1 & 3.33 & 21 & - & - \\
& DG2 & - & - & 1.55 & 17 \\
\hline \multirow{4}{*}{ Trustworthy } & TG & 3.50 & 14 & 1.84 & 17 \\
& DG1 & 3.44 & 18 & - & - \\
& DG2 & - & - & 1.55 & 18 \\
\hline Untrustworthy & TG & 3.63 & 19 & 1.10 & 14 \\
& DG1 & 3.00 & 15 & - & - \\
& DG2 & - & - & 1.78 & 13 \\
\hline
\end{tabular}


Focusing now attention on the second divide, the trustworthy individuals send back more generously than untrustworthy individuals in the TG (1.84), but not in the DG2 (1.55) - as one would have expected by associating higher trustworthiness to higher "altruism" - where the untrustworthy individuals to return a larger amount than in the TG (1.10 and 1.78, respectively). This evidence suggests that strategic behaviour more than altruism drives behaviour. In fact, for the "trustworthy" the reciprocity motive does actually play a more important role than the altruistic sentiment. Given that in the DG2 the amounts received by second movers were not decided by the potential beneficiaries of the dictators magnanimity, 'trustworthy' individuals are rewarding the flesh and blood Sender, even though they don't know precisely who that is, more generously than they reward an unidentified individual who is not physically present - treating the amount received as manna. Similarly, but on the other facet of "strong reciprocity", by sending back a smaller amount than the "trustworthy" in the TG and a larger in the DG2, the "untrustworthy" seems inclined to punish a selfish sender.

Overall, the behaviour of the trustworthy highlights reward, the positive side of reciprocity, while the behaviour of the trusting who feels betrayed and of the untrustworthy who stick to a sceptical view about his social environment both point to punishment, the dark side of reciprocity.

\section{Concluding remarks}

Our experimental design had two aims. First, to find out whether, and possibly to what extent, answers to a questionnaire about attitudes to trusting and reciprocating predict the subjects' behaviour; second, by comparing behaviour in Trust and Dictator Game, to disentangle the strategic motivation (the intention of the trustor to elicit benevolence from the trustee, and the trustee's interest in reciprocating to generous or not so generous invoice) from the altruistic motivation.

An important outcome of our investigation is that no simple or direct correlation shows up between behavioural trust or trustworthiness and attitudinal trust or expected reciprocity, as resulting from the self-declared disposition to trust and comply with civic virtues. From the statistical and econometric treatment of behavioural evidence and answers to the questionnaire, we observe that the link between the questionnaire and experimental sessions is more subtle that the mere correlation between average attitudes and average behaviours. 
The relevant evidence starts blossoming after that the two main motivations for trust and reciprocity behaviour - strategic reasoning and altruism - have been separated out. In fact, by dividing subjects according to the varying degree witnessed by answers of disposition to trust and to be trustworthy, the self-declared "trusting" tend to "invest" more than the "prudent", and the self-declared "trustworthy" are more inclined to reciprocate than the "untrustworthy". More specifically, as for individuals playing as trustor, we have found a neat divide between subjects who self-report a positive disposition towards trusting (and then are willing to send a significant amount to the trustee) and those who instead are very reluctant to "invest" in the strategic relationship of the Trust Game (and thus send a small amount). Similarly, as for individuals playing as trustee, they do not seem to be influenced much - on average - by the amount they received, but in case of a small amount received they seem motivated by the desire to punish the sender, as they return much less than had received. The "trustworthy" are inclined to strategic behaviour - both in the positive sense of rewarding the sender, and the negative one of punishing - more than "to be good to others", as could have been manifested by a significant correlation between the amount returned in the DG2 and the amount returned in the TG. Overall, we find that strategic interaction is more effective than social preferences in motivating the subjects behaviour. The more trusting are the subjects, according to their answers to the questionnaire, the more they send as trustors, and the less they send back as trustee in case the senders deserves to be punished for having sent a small amount.

An important insight stemming from the analysis is that the self-evaluation of one's own disposition to trust, and the degree of compliance with civic virtues, appear to separately motivate people. In other words, we are not allowed to forecast that the very same subject declaring a high disposition to trust - the "trusting" individuals - should also necessarily express high trustworthiness; and the other way round, a subject who self-reports as a "trustworthy" individual should not be expected to behave as "investing" much when playing the role of the trustor. The tentative indication of our results is that individuals are "multiple selves" (Elster, 1986), the parts of which do not necessarily communicate and agree on behaviour in social interactions.

Finally, on methodological grounds, our investigation cast some doubts as to the possibility of establishing a direct link between attitudinal and experimental evidence, as far as trust and trustworthiness are concerned. The answers to a questionnaire predict behaviour in experimental sessions only to a limited extent. The information conveyed by a survey appears to be much more powerful in detecting motivation for behaviour after the two motivational components have been separated out in the statistical evaluation of the sessions. As for further research work on this topic, the message is to extensively use the attitudinal measures in analysing experimental evidence. 


\section{References}

Bacharach M., G. Guerra, and D.J. Zizzo (2001), Is Trust Self-Fulfilling? An Experimental Study, mimeo.

Berg J., J. Dickhault, K. McCabe (1995), "Trust, reciprocity, and social history", Games and Economic Behavior, 10:122-142.

Charness G. and M. Rabin (2005), "Expressed preferences and behavior in experimental games", Games and Economic Behavior, 53: 151-169.

Ciriolo E. (2007), "Inequity aversion and trustees'reciprocity in the trust game", European Journal of Political Economy, 23: 1007-1024.

Coleman J.C. (1990), Foundations of Social Theory, The Belknap Press of Harvard University Press, Cambridge (Mass.).

Cox J.C. (2004), "How to identify trust and reciprocity", Games and Economic Behavior, 46: 260281.

Davidson, R. and J.G. McKinnon (1986), Estimation and Inference in Econometrics, Oxford University Press.

Elster J. (1986), "Introduction”, in Elster J. (ed), The Multiple Self, Cambridge University Press, Cambridge.

Falk A., Fehr E. and U. Fischbacher (2003), "On the nature of fair behaviour", Economic Inquiry, 41: 20-6.

Farina F. and P. Sbriglia (2008), "Conditional Cooperation in a Sequential Move Game", International Review of Economics, 55: 149-165.

Fehr E. and U. Fischbacher (2002), "Why Social Preferences Matter - The Impact of Non-Selfish Motives on Competition, Cooperation and Incentives", Economic Journal, C1-C33.

Fehr E., U. Fischbacher, B. Von Schupp, G. G. Wagner (2003), "A Nation-Wide Laboratory. Examining Trust and Trustworthiness by Integrating Behavioral Experiments into Representative Surveys", Cesifo Working Paper n. 866.

Fehr E. and K.M. Schmidt (1999), "A Theory of Fairness, Competition, and Cooperation", Quarterly Journal of Economics, 114: 816-818.

Fehr E. and K.M. Schmidt (1999), "Experimental Evidence and New Theories", in S.-C. Kolm and J.M. Ythier (eds.), Handbook of the Economics of Giving, Altruism and Reciprocity, Vol.I, NorthHolland, Amsterdam.

Fehr E., U. Fischbacher, B. von Rosenbladt, J. Schupp, G.G. Wagner (2003), A Nation-Wide Laboratory. Examining Trust and Trustworthiness by Integrating Behavioral Experiments into Representative Surveys, Cesifo W.P. n. 866.

Glaeser E.L., D. Laibson, J.A. Scheinkman, C.L. Soutter (2000), "Measuring Trust", Quarterly Journal of Economics, 65: 811-846.

Goeree J.K. and C.A. Holt (2001), "Ten Little Treasures of Game Theory and Ten Intuitive Contradictions", American Economic Review, 91: 1402-1422.

Gneezy U., W. Guth, F. Verboven (2000), "Present or investments? An experimental analysis", Journal of Economic Psychology, 21: 481-493.

Holt C.A. and S.K. Laury (2002), Risk Aversion and Incentive Effects, W.P. n.

Lazzarini S.G., R. Madalozzo, R. Artes, J. De Oliveira Sequeira (2005), "Measuring Trust: An Experiment in Brazil", Brazilian Journal of Applied Economics, 9: 153-169.

McCabe K., M.L. Rigdon, Vernon L. Smith (2003), "Positive reciprocity and intentions in trust games", Journal of Economic Behavior and Organization, 52: 267-275.

von Neumann J. and O. Morgenstern (1944), Theory of Games and Economic Behavior, Princeton University Press, Princeton.

Rabin M. (1993), "Incorporating fairness in game theory and economics", American Economic Review, 83: 1281-1302.

Sapienza P., A. Toldra, L. Zingales (2007), Understanding Trust, NBER W.P. n. 13387. 
Simon H.A.(1956), “A Comparison of Game Theory and Learning Theory”, Psychometrica, 21, 267-272. 
Appendix: Trust \& reciprocity questions

\begin{tabular}{|c|c|}
\hline Question & Range/values \\
\hline \multicolumn{2}{|l|}{ Trust } \\
\hline $\begin{array}{l}\text { In general, would you say that you can trust most people or } \\
\text { that one can never be too careful? }\end{array}$ & $\begin{array}{l}1=\text { trust } \\
2=\text { prudent } \\
(0=\text { don't know })\end{array}$ \\
\hline \multicolumn{2}{|l|}{ How much trust do you have in the following groups: } \\
\hline - Your Family & \multirow{4}{*}{$\begin{array}{l}1=\text { no trust } \\
2=\text { trust a little } \\
3=\text { trust quite a lot } \\
4=\text { trust completely } \\
(0=\text { don't know })\end{array}$} \\
\hline - People you know & \\
\hline - New acquaintances & \\
\hline - Immigrants & \\
\hline Ethnic Diversity? & $\begin{array}{l}\text { From } \mathbf{1}=\text { lowers social } \\
\text { harmony } \\
\text { To } \mathbf{1 0}=\text { is valuable }\end{array}$ \\
\hline \multicolumn{2}{|l|}{ Which of the following behaviours may be justified: } \\
\hline $\begin{array}{l}\text { - To try to obtain benefits form the State to which you are not } \\
\text { entitled }\end{array}$ & \multirow{8}{*}{$\begin{array}{l}\text { From } \mathbf{1}=\text { never justified } \\
\text { To } \mathbf{1 0}=\text { always justified } \\
(0=\text { don't know })\end{array}$} \\
\hline - To not pay your taxes & \\
\hline $\begin{array}{l}\text { - To take and drive someone else's car without their } \\
\text { permission }\end{array}$ & \\
\hline - To make false statements to further ones own interests & \\
\hline - To have an extra-marital affair & \\
\hline - To accept a bribe & \\
\hline - To pay for services 'under the counter' to avoid paying taxes & \\
\hline - To not pay for your bus ticket & \\
\hline \multicolumn{2}{|l|}{ How much trust do you have in the following Institutions: } \\
\hline - Government & \multirow{4}{*}{$\begin{array}{l}1=\text { no trust } \\
2=\text { trust a little } \\
3=\text { trust quite a lot } \\
4=\text { trust completely } \\
(0=\text { don't know })\end{array}$} \\
\hline - Parliament & \\
\hline - Political Parties & \\
\hline - Civil Service/Servants & \\
\hline $\begin{array}{l}\text { Most people a) try to take advantage of you every time they } \\
\text { can; or, b) try to behave correctly towards you }\end{array}$ & $\begin{array}{l}\text { From } \mathbf{1}=\text { always try to } \\
\text { take advantage } \\
\text { To } \mathbf{1 0}=\text { always try to } \\
\text { behave correctly } \\
(0=\text { don't know })\end{array}$ \\
\hline
\end{tabular}




\section{Labsi Working Papers}

\section{ISSN 1825-8131 (online version) $\mathbf{1 8 2 5 - 8 1 2 3}$ (print version)}

Issue

n. $1 / 2005$

ก. $2 / 2005$

n. $3 / 2005$

n. $4 / 2005$

n. $5 / 2006$

ก. $6 / 2006$

ก. $7 / 2006$

ก. $8 / 2006$

ก. $9 / 2006$

n. $10 / 2006$

n. $11 / 2006$

n. $12 / 2007$

n. $13 / 2007$

n. $14 / 2007$
Author

Roberto Galbiati

Pietro Vertova

Marco Casari

Luigi Luini

Carlo Altavilla

Luigi Luini

Patrizia Sbriglia

Roberto Ricciuti

Alessandro Innocenti

Maria Grazia Pazienza

Brice Corgnet

Angela Sutan

Arvind Ashta

Brian Kluger

Daniel Friedman

Gunduz Caginalp

Vladimira I lieva

Gerlinde Fellner

Erik Theissen

Robin Pope

Reinhard Selten

Sebastian Kube

J ürgen von Hagen

Niall O'Higgins

Patrizia Sbriglia

Mauro Caminati

Alessandro Innocenti

Roberto Ricciuti

Klaus Abbink

Jordi Brandts

Jens Großer

Arthur Schram
Title

Law and Behaviours in Social Dilemmas: Testing the Effect of Obligations on Cooperation (April 2005)

Group Cooperation Under Alternative Peer

Punishment Technologies: An Experiment (J une 2005)

Social Learning in Market Games (J une 2005)

Bringing Macroeconomics into the Lab (December 2005)

Altruism and Gender in the Trust Game (February 2006)

The power of words in financial markets: soft versus hard communication, a strategy method experiment (April 2006)

Financial Engineering and Rationality: Experimental Evidence Based on the Monty Hall Problem (April 2006)

The dynamics of trader motivations in asset bubbles (April 2006)

Short Sale Constraints, Divergence of Opinion and Asset Values: Evidence from the Laboratory (April 2006)

Experimental Evidence on the Benefits of

Eliminating Exchange Rate Uncertainties and Why

Expected Utility Theory causes Economists to Miss Them (May 2006)

Are I mitative Strategies Game Specific?

Experimental Evidence from Market Games (October 2006)

Drift and Equilibrium Selection with Human and Virtual Players (April 2007)

Political Autonomy and Independence: Theory and Experimental Evidence (September 2007)

Public Opinion Polls, Voter Turnout, and Welfare:

An Experimental Study (September 2007) 

Nicolao Bonini
Ilana Ritov
Michele Graffeo
n. 16/2007 Jaromir Kovarik
Vivian Lei
n. 17/2007 Steven Tucker
Filip Vesely
n. 18/2007 Joana Pais
Ágnes Pintér
Antonio Cabrales
n. 19/2007 Rosemarie Nagel
J osé V. Rodrìguez Mora
n. 20/2008 Carla Marchese
Marcello Montefiori
Francesco Farina

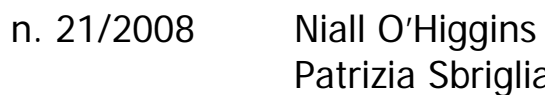
Alessandro Innocenti
n. 22/2008 Alessandra Rufa
Jacopo Semmoloni
n. 23/2008 Astri Hole Drange

When does a referent problem affect willingness to pay for a public good? (September 2007)

Belief Formation and Evolution in Public Good Games (September 2007)

Forgive or Buy Back: An Experimental Study of Debt Relief (September 2007)

School Choice and Information. An Experimental Study on Matching Mechanisms (September 2007)

It is Hobbes not Rousseau: An Experiment on Social Insurance (September 2007)

Voting the public expenditure: an experiment (May 2008)

Eliciting motives for trust and reciprocity by attitudinal and behavioural measures (J une 2008)

Cognitive Biases and Gaze Direction: An Experimental Study (J une 2008)

How do economists differ from others in distributive situations? (September 2008) 


\section{LABSI WORKING PAPERS}

ISSN 1825-8131 (ONLINE VERSION) 1825-8123 (PRINT VERSION)

LABSI EXPERIMENTAL ECONOMICS LABORATORY UNIVERSITY OF SIENA

PIAZZA S. FRANCESCO, 753100 SIENA (ITALY)

http://www.labsi.org labsi@unisi.it 